Marquette University

e-Publications@Marquette

Biomedical Engineering Faculty Research and

Publications

Biomedical Engineering, Department of

7-1-2004

\title{
Stent Design Properties and Deployment Ratio Influence Indexes of Wall Shear Stress: a Three-Dimensional Computational Fluid Dynamics Investigation within a Normal Artery
}

\author{
John F. LaDisa \\ Marquette University, john.ladisa@marquette.edu \\ Lars E. Olson \\ Marquette University, lars.olson@marquette.edu \\ Ismail Guler \\ Douglas Anthony Hettrick \\ Marquette University \\ Said H. Audi \\ Marquette University, said.audi@marquette.edu
}

See next page for additional authors

Follow this and additional works at: https://epublications.marquette.edu/bioengin_fac

Part of the Biomedical Engineering and Bioengineering Commons

\section{Recommended Citation}

LaDisa, John F.; Olson, Lars E.; Guler, Ismail; Hettrick, Douglas Anthony; Audi, Said H.; Kersten, Judy R.; Warltier, David C.; and Pagel, Paul S., "Stent Design Properties and Deployment Ratio Influence Indexes of Wall Shear Stress: a Three-Dimensional Computational Fluid Dynamics Investigation within a Normal Artery" (2004). Biomedical Engineering Faculty Research and Publications. 217.

https://epublications.marquette.edu/bioengin_fac/217 


\section{Authors}

John F. LaDisa, Lars E. Olson, Ismail Guler, Douglas Anthony Hettrick, Said H. Audi, Judy R. Kersten, David C. Warltier, and Paul S. Pagel 
Marquette University

e-Publications@Marquette

\section{Biomedical Engineering Faculty Research and Publications/College of} Engineering

This paper is NOT THE PUBLISHED VERSION; but the author's final, peer-reviewed manuscript. The published version may be accessed by following the link in the citation below.

Journal of Applied Physiology, Vol. 97, No. 1 (July 2004): 424-430. DOI. This article is (C American Physiological Society and permission has been granted for this version to appear in $\underline{\mathrm{e}-}$

Publications@Marquette. American Physiological Society does not grant permission for this article to be further copied/distributed or hosted elsewhere without the express permission from American Physiological Society.

\section{Stent design properties and deployment ratio influence indexes of wall shear stress: a three- dimensional computational fluid dynamics investigation within a normal artery}

John F. LaDisa, Jr.

Departments of Anesthesiology, Department of Biomedical Engineering, Marquette University, Milwaukee, Wisconsin

Lars E. Olson

Department of Biomedical Engineering, Marquette University, Milwaukee, Wisconsin

Ismail Guler

Boston Scientific Corporation, Maple Grove, Minnesota

Douglas A. Hettrick 
Departments of Anesthesiology, Department of Biomedical Engineering, Marquette University, Milwaukee, Wisconsin

\section{Said H. Audi}

Pulmonary and Critical Care Medicine, Department of Biomedical Engineering, Marquette University, Milwaukee, Wisconsin

\section{Judy R. Kersten}

Departments of Anesthesiology, Pharmacology and Toxicology, Medicine, Division of Cardiovascular Diseases, Medical College of Wisconsin, Clement J. Zablocki Veterans Affairs Medical Center, Milwaukee, WI

\section{David C. Warltier}

Departments of Anesthesiology, Department of Biomedical Engineering, Marquette University, Milwaukee, Wisconsin

Pharmacology and Toxicology, Medicine, Division of Cardiovascular Diseases, Medical College of Wisconsin, Clement J. Zablocki, Veterans Affairs Medical Center, Milwaukee, WI

\section{Paul S. Pagel}

Departments of Anesthesiology, Department of Biomedical Engineering, Marquette University, Milwaukee, Wisconsin

\section{Abstract}

Restenosis limits the effectiveness of stents, but the mechanisms responsible for this phenomenon remain incompletely described. Stent geometry and expansion during deployment produce alterations in vascular anatomy that may adversely affect wall shear stress (WSS) and correlate with neointimal hyperplasia. These considerations have been neglected in previous computational fluid dynamics models of stent hemodynamics. Thus we tested the hypothesis that deployment diameter and stent strut properties (e.g., number, width, and thickness) influence indexes of WSS predicted with three-dimensional computational fluid dynamics. Simulations were based on canine coronary artery diameter measurements. Stent-to-artery ratios of 1.1 or 1.2:1 were modeled, and computational vessels containing four or eight struts of two widths ( 0.197 or $0.329 \mathrm{~mm}$ ) and two thicknesses $(0.096$ or $0.056 \mathrm{~mm}$ ) subjected to an inlet velocity of $0.105 \mathrm{~m} / \mathrm{s}$ were examined. WSS and spatial WSS gradients were calculated and expressed as a percentage of the stent and vessel area. Reducing strut thickness caused regions subjected to low WSS $\left(<5 \mathrm{dyn} / \mathrm{cm}^{2}\right)$ to decrease by $\sim 87 \%$. Increasing the number of struts produced a 2.75 -fold increase in exposure to low WSS. Reducing strut width also caused a modest increase in the area of the vessel experiencing low WSS. Use of a 1.2:1 deployment ratio increased exposure to low WSS by 12 -fold compared with stents implanted in a 1.1:1 stent-to-vessel ratio. Thinner struts caused a modest reduction in the area of the vessel subjected to elevated WSS gradients, but values were similar for the other simulations. The results suggest that stent designs that reduce strut number and thickness are less likely to subject the vessel to distributions of WSS associated with neointimal hyperplasia.

Approximately $20 \%$ of the nearly $1,000,000$ stents deployed annually develop restenosis due to neointimal hyperplasia $(8,13,15,42,48)$. Rates of restenosis vary with stent design and geometry $(32,39)$. These factors have also been identified as important predictors of neointimal hyperplasia $(17,50)$. Vascular geometry influences distributions of wall shear stress (WSS), as evidenced by branching and curvature that produce regions of low WSS. These alterations adversely affect the preferential flow environment of intravascular cells and correlate with sites of neointimal hyperplasia $(21,31,33)$. Notably, all stents must be deployed to a diameter greater than that of the native vessel to securely anchor the device against the vessel wall. 
Computational fluid-dynamics (CFD) studies of stented vascular segments performed to date $(4,10,23)$ have not addressed this technical issue. However, it is highly likely that the requirement for stent expansion beyond the luminal diameter may cause severe reductions in WSS within the stented region of the vessel. Several models in vivo have adopted a stent-to-artery diameter ratio range of 1.1-1.2:1 to limit vascular damage during deployment $(11,47)$, but the theoretical influence of geometric stent properties and the impact of stentexpansion diameter on distributions of WSS have not yet been comprehensively investigated. We tested the hypothesis that differences in the geometric design of an implanted stent (e.g., number, width, and thickness of struts) influence acute distributions of WSS predicted with three-dimensional (3D) CFD modeling and compared these results with those produced by a different stent-to-artery deployment ratio.

\section{METHODS}

\section{Construction of stented vessels.}

CFD models were created from measurements of canine left anterior descending coronary artery blood flow and diameter as described previously (24). Stented vessels were generated with an automated geometricconstruction and mesh-generation algorithm custom designed by Matlab (Mathworks, Natick, MA). On execution of the automated algorithm, a graphical user interface was launched, which allowed manual entry of several parameters including the number, width, and thickness of stent struts to be used in creation of the computational mesh. All computational vessels were composed of structured hexahedral control volumes and exploited symmetric stent and vessel properties to model one-forth of the computational vessel. Computational vessels were created that consisted of four or eight struts using two strut widths (0.197 or $0.329 \mathrm{~mm}$ ) and two different degrees of protrusion into the flow domain $(0.096$ or $0.056 \mathrm{~mm}$ ) (Table 1, Fig. 1). The stent length was $16 \mathrm{~mm}$ for all simulations, and the diameter of the native vessel was $2.74 \mathrm{~mm}$. Computational geometries used to examine the impact of expanded stent diameter were created by stent-to-vessel ratios of 1.1 and 1.2:1 $(11,47)$.

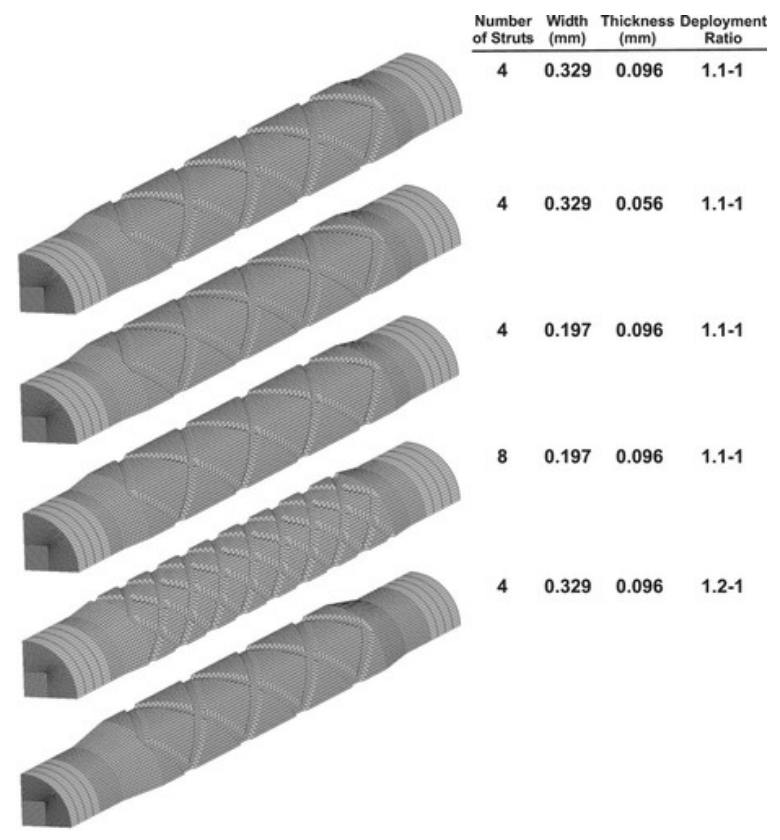

Fig. 1.Computational geometries generated with an automated geometric-construction and mesh-generation algorithm custom designed in Matlab. 
Table 1. Stent and vessel properties and quantification of WSS

\begin{tabular}{|l|l|l|l|l|l|}
\hline Index & & & & & \\
\hline Number of struts & 4 & 4 & 4 & 8 & 4 \\
\hline Strut width, $\mathrm{mm}$ & 0.329 & 0.329 & 0.197 & 0.197 & 0.329 \\
\hline Strut thickness, $\mathrm{mm}$ & 0.096 & 0.056 & 0.096 & 0.096 & 0.096 \\
\hline Stent-to-artery ratio & $1.1: 1$ & $1.1: 1$ & $1.1: 1$ & $1.1: 1$ & $1.2: 1$ \\
\hline Biologically active area, $\mathrm{mm}^{2}$ & 47 & 47 & 51 & 44 & 53 \\
\hline Stent area, $\mathrm{mm}^{2}$ & 11 & 11 & 7 & 15 & 11 \\
\hline Stent/total area, $\%$ & 23 & 23 & 14 & 35 & 21 \\
\hline WSS of $<5 \mathrm{dyn} / \mathrm{cm}^{2}, \mathrm{~mm}^{2}$ & 1.11 & 0.14 & 1.35 & 3.72 & 13.2 \\
\hline WSS of $<5 \mathrm{dyn} / \mathrm{cm}^{2} / \mathrm{stent}^{2}$ area, $\%$ & 10 & 1 & 19 & 25 & 116 \\
\hline WSS of $<5 \mathrm{dyn} / \mathrm{cm}^{2} / \mathrm{total}^{2}$ area, $\%$ & 2.4 & 0.3 & 2.7 & 8.5 & 25 \\
\hline WSSG of $>20 \mathrm{dyn} / \mathrm{cm}^{3}, \mathrm{~mm}{ }^{2}$ & 18 & 15 & 19 & 16 & 21 \\
\hline WSSG of $>20 \mathrm{dyn} / \mathrm{cm}^{3} / \mathrm{stent}^{2}$ area, $\%$ & 155 & 131 & 260 & 106 & 182 \\
\hline WSSG of $>20 \mathrm{dyn} / \mathrm{cm}^{3} /$ total area, $\%$ & 38 & 32 & 37 & 37 & 39 \\
\hline
\end{tabular}

WSS, wall shear stress; WSSG, WSS gradients.

\section{Computational model simulations.}

Simulations were performed with the commercially available software package CFD-ACE (CFDRC, Huntsville, AL). This software uses a finite-volume approach to solve the Navier-Stokes equations at the center of each hexahedral control volume. A steady-state velocity value corresponding to average blood flow velocity during one cardiac cycle in the canine left anterior descending coronary artery under normal resting conditions $(0.105$ $\mathrm{m} / \mathrm{s})(24)$ and on the order of that measured after acute stent implantation in humans (44) was imposed as plug flow at the vessel inlet. Additional length $(L)$ was added to all arteries to allow for fully developed flow using the equation $L=0.06 \cdot \operatorname{Re} \cdot d$, where $L$ is the length, Re is the Reynolds number, and $d$ is the vessel inlet diameter (9). The Reynolds number is a dimensionless parameter that classifies the transition from laminar to turbulent flow in tubes based on the relation $\operatorname{Re}=\rho \bar{v} d / \mu$, where $\rho, \mu$, and $\bar{v}$ are the density, viscosity, and mean velocity of the fluid, respectively, and all influence the length that must be added to the computational vessel inlet to ensure that flow no longer varies in the axial direction before entering the stent. Computational simulations were conducted assuming incompressible flow of a Newtonian fluid with a density of $1,060 \mathrm{~kg} / \mathrm{m}^{3}$ and viscosity of 3.7 CP (23).

\section{Calculation of indexes of WSS.}

WSS was determined as the product of viscosity and shear rate as previously described (23). Shear rate $(\gamma)$ was calculated using the second invariant of the strain rate tensor. Therefore

$$
\begin{gathered}
\dot{\gamma}=\left\{2\left[(\partial u / \partial x)^{2}+\partial(\partial v / \partial y)^{2}+(\partial w / \partial z)^{2}\right]+(\partial u / \partial y+\partial v / \partial x)^{2}(\partial u / \partial z+\partial w / \partial x)^{2}\right. \\
\left.+(\partial v / \partial z+\partial w / \partial y)^{2}\right\}^{1 / 2}
\end{gathered}
$$

where $u, v$, and $w$ are the $x, y$, and $z$ components of velocity vector $\mathbf{u}$, respectively. This definition accounts for pure shear as well as extensional or elongational deformation in the flow domain.

Spatial WSS gradients (WSSG) were calculated during postprocessing as discussed previously (18). WSSG were used to quantify the influence of nonuniform hemodynamic forces on adjacent intravascular cells and may correlate with the location of neointimal hyperplasia in vivo $(5,45,46)$. Spatial changes in WSS that act predominantly in axial and circumferential directions have the most potential to disrupt intracellular junctions as 
discussed previously (26). Therefore, WSSG were calculated as $\left[\left(\partial \tau_{w, z} / \partial z\right)+\left(\partial \tau_{w, \theta} / \partial \theta\right)\right]^{1 / 2}$,

where $\tau_{w, z}$ and $\tau_{w, \vartheta}$ represent WSS in the axial and circumferential directions, respectively.

\section{Quantification of simulation results.}

The threshold for comparing distributions of low WSS between simulations was established at 5 $\mathrm{dyn} / \mathrm{cm}^{2}$ because vascular regions subjected to WSS slightly below this value have been shown to strongly correlate with sites of intimal thickening $(20,21)$. Regions of low WSS were then expressed as percentages of the stent and vessel area within the stented region. The percent distribution of moderate and high WSS for each simulation was also quantified. High WSS was defined as those values between 8 and $12 \mathrm{dyn} / \mathrm{cm}^{2}$ that are unlikely to contribute to neointimal hyperplasia $(20,31)$. Moderate values of WSS were defined as those occurring between 5 and $8 \mathrm{dyn} / \mathrm{cm}^{2}$, because these values may theoretically decrease in regions adjacent to stent struts if geometric stent or vessel properties were altered.

WSSG have also been used previously to examine the hypothesis that normally confluent cells react to nonuniform distributions of WSS in a way that promotes neointimal hyperplasia $(7,37,45)$. The percentage of the vessel wall subjected to WSSG values above $20 \mathrm{dyn} / \mathrm{cm}^{3}$ was quantified and compared between simulations in the present investigation. WSSG of this order of magnitude generated from two separate studies were found to correlate with areas of neointimal hyperplasia in the toe region of an end-to-side arterial anastomosis $(22,25,37)$. WSSG-observed overlying stent struts were excluded from the analysis because these areas would not acutely contain biologically active tissue in vivo.

\section{RESULTS}

Distributions of WSS observed during CFD simulations are illustrated in Fig. 2. The highest values of WSS were localized over the surface of stent struts and the distal stent-vessel transition for all simulations. In contrast, stagnation zones surrounded the stent struts independent of the strut width, thickness, number, or stent-toartery diameter ratio. A reduction in stent strut thickness produced a decrease in the percentage of the vessel exposed to low WSS ( $2.4 \%$ for $0.096 \mathrm{~mm}$ vs. $0.3 \%$ for $0.056 \mathrm{~mm}$; Table 1 ). The area of the computational vessel subjected to WSS of $<5 \mathrm{dyn} / \mathrm{cm}^{2}$ increased when the number of struts doubled from 4 to $8\left(1.35 \mathrm{vs} .3 .72 \mathrm{~mm}^{2}\right)$. Reducing the width of stent struts from 0.329 to $0.197 \mathrm{~mm}$ also exposed the vessel to a greater area of WSS of $<5 \mathrm{dyn} / \mathrm{cm}^{2}$ (1.11 vs. $1.35 \mathrm{~mm}^{2}$ ). Expansion of the stent to a 1.2:1 ratio markedly increased the area of WSS of $<5$ $\mathrm{dyn} / \mathrm{cm}^{2}$ compared with the 1.1:1 stent-to-vessel ratio (13.2 vs. $1.11 \mathrm{~mm}^{2}$ ).

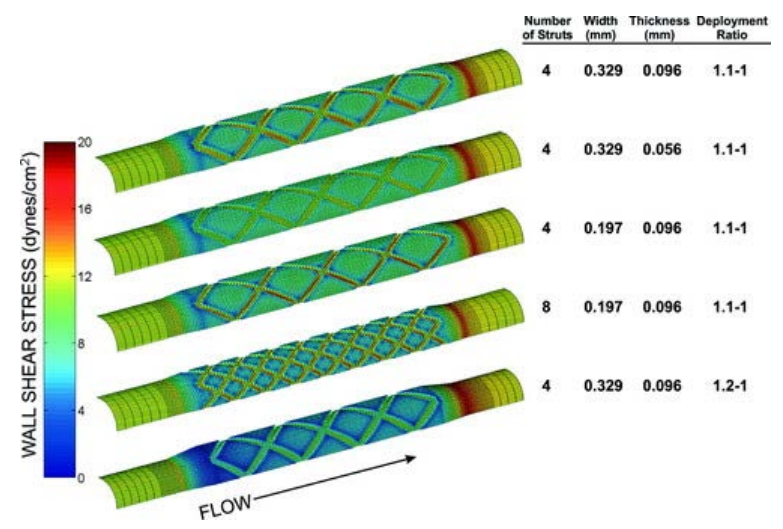

Fig. 2. Theoretical influence of various stent design parameters, including number, width, and thickness of struts and stent-to-artery diameter ratio on the distribution of wall shear stress (WSS) in computational fluid dynamics vessels. 
The distribution of each vessel exposed to low, moderate, and high WSS expressed as a percentage of the biologically active vessel area within the stented region is depicted in Fig. 3 . The majority of the vessel wall was subjected to WSS values between 5 and $8 \mathrm{dyn} / \mathrm{cm}^{2}$ when the stent thickness was $0.096 \mathrm{~mm}$. Altering the stent width and deployment ratio did not substantially affect the percent distribution of WSS in this range. Reducing strut thickness from 0.096 to $0.056 \mathrm{~mm}$ increased the percentage of the vessel wall exposed to WSS $>8 \mathrm{dyn} / \mathrm{cm}^{2}$. Conversely, increasing the number of struts from 4 to 8 decreased the axial and circumferential strut spacing and reduced the percentage of the vessel exposed to WSS of $>8 \mathrm{dyn} / \mathrm{cm}^{2}$.

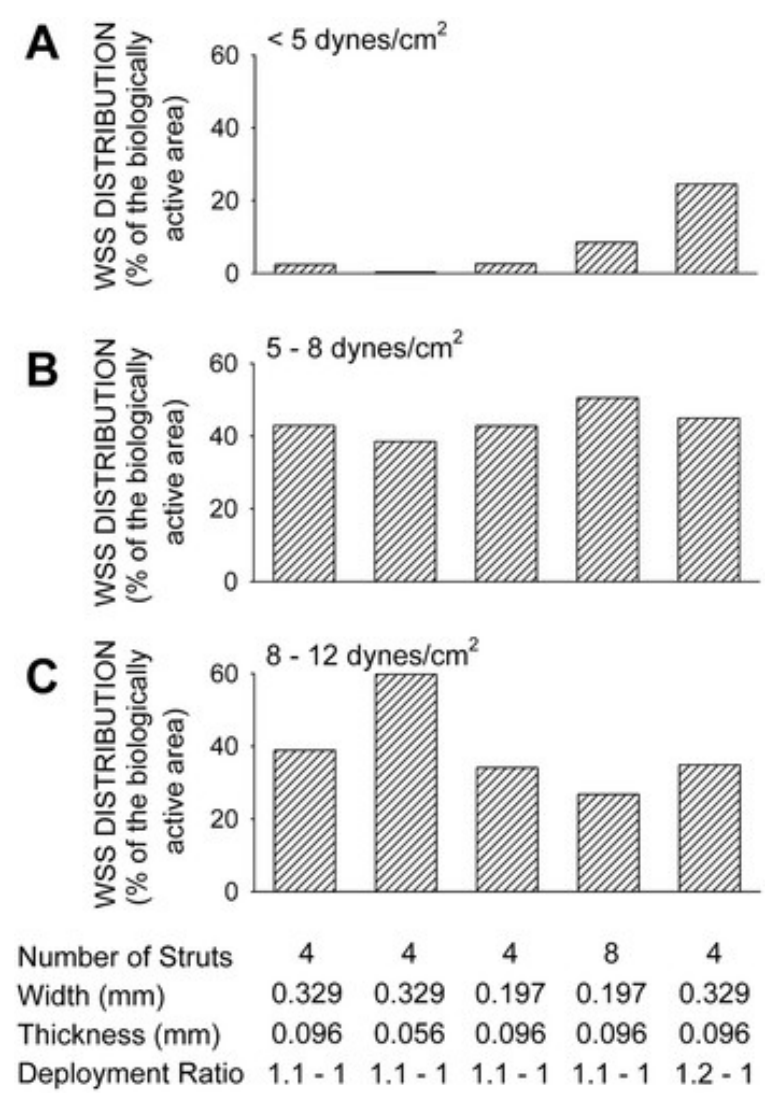

Fig. 3. Distribution of the vessel wall exposed to low $\left(<5 \mathrm{dyn} / \mathrm{cm}^{2} ; A\right)$, moderate (between 5 and $\left.8 \mathrm{dyn} / \mathrm{cm}^{2} ; B\right)$, and high (between 8 and $12 \mathrm{dyn} / \mathrm{cm}^{2} ; C$ ) WSS expressed as a percentage of the biologically active vessel area within the stented portion of the vessel.

WSSGs for each simulation are illustrated in Fig. 4. Regions of elevated WSSG were noted at the inlet and outlet of the stented region. Concentric proximal and distal regions of elevated WSSG $\left(>150 \mathrm{dyn} / \mathrm{cm}^{3}\right)$ that occurred as a result of stent expansion were observed in each simulation. WSSG were also elevated bordering the stentvessel transitions at the stent inlet and outlet. The amount of the vessel wall exposed to WSSG of $>20$ $\mathrm{dyn} / \mathrm{cm}^{3}$ was modestly reduced when strut thickness was decreased (38 vs. 32\% for 0.096 and $0.056 \mathrm{~mm}$, respectively). The amount of the vessel exposed to elevated WSSG was otherwise similar for all other stent geometries investigated (Table 1). 


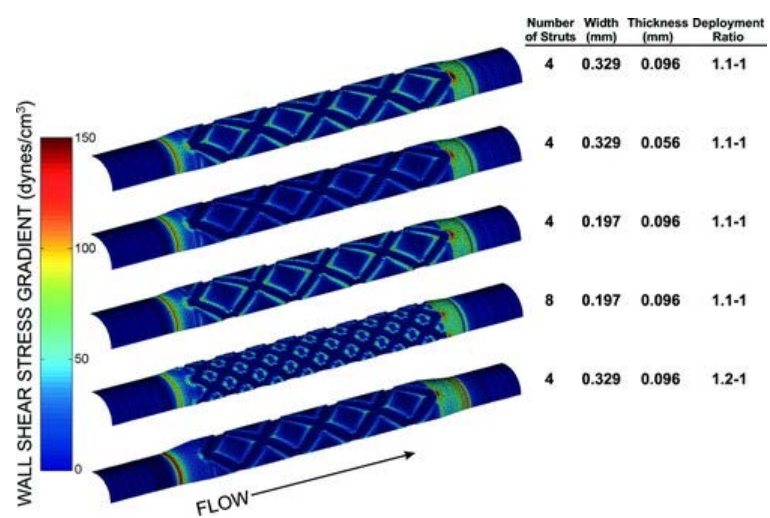

Fig. 4.Spatial WSS gradients (WSSG) imparted on the surface of the computational vessel. The distribution of WSSG and the associated quantification (Table 1) do not consider spatial WSSG over or along the length of the stent struts because these regions do not contain biologically active tissue.

\section{DISCUSSION}

Restenosis after stent implantation remains an important clinical problem. Evidence collected to date suggests that restenosis rate varies with stent type, local vessel geometry spatially correlates with regions of neointimal hyperplasia, and vascular response to injury is modulated by shear stress $(17,21,27,30,50)$. These data imply that the geometry of the implanted stent may cause altered distributions of WSS that potentially contribute to the subsequent development of neointimal hyperplasia. To our knowledge, the present investigation is the first to use 3D CFD modeling to examine whether differences in stent geometry or the stent-to-artery deployment ratio affect WSS distributions within the stented region. The results indicate that overexpansion of the stent markedly increases the area of the vessel subjected to low WSS. Interestingly, increased deployment pressure is associated with vascular damage, an index that influences the amount of neointimal hyperplasia $(6,12,14)$. The present results also indicate that the number, width, and thickness of stent struts impart distinctive patterns of shear stress along the vessel wall with a realistic deployment ratio of 1.1:1. These results are consistent with previous flow visualization and in vivo studies $(4,36)$ and further suggest that, although the geometric disparity between various stent designs varies by $<90 \mu \mathrm{m}$ (from 0.056 to $0.14 \mathrm{~mm}$ ) $(17,32)$, these characteristics may theoretically contribute to observed differences in restenosis rates between designs.

The present findings indicate that a smaller percentage of the vascular wall is exposed to low WSS that is associated with vascular remodeling when the number and thickness of stent struts is reduced. These results suggest that a stent with thin radial properties and fewer stent intersections may be hemodynamically advantageous. A previous study demonstrated that endothelialization after implantation of a simplified stent on a flat plate was dependent on stent thickness in vitro (43). The present results suggest that reductions in WSS over the stent struts due to decreased strut thickness may mediate this endothelialization process. In contrast, a reduction in stent strut width resulted in a larger percentage of the vascular wall being subjected to WSS values of $<5 \mathrm{dyn} / \mathrm{cm}^{2}$ in the present investigation. These findings imply that a reduction in stent width exposes more of the luminal surface to distributions of low WSS caused by the presence of the stent struts. Wider struts also increase the spatial potential for flow above the strut to become established by enabling streamlines to align in this location. The present results confirm and extend our previous findings that characterized near wall velocity vectors in a similar stented 3D CFD vessel model (23). The present observation suggesting an advantageous reduction in low WSS with wider struts is also supported by results from two-dimensional CFD models using single and multiple struts of similar width and thickness subjected to flow of an equivalent Reynolds number (unpublished observations). These results imply that increasing the width of stent struts may improve fluid 
dynamics, but actual deployment of stents with wider strut designs may contribute to greater local vascular damage.

Regions of low WSS were most pronounced in the proximal portion of the stent and were less dramatic and similar within each axial stent diamond for the remainder of the stent length. These results are consistent with a previous in vitro study (1) and suggest that the inlet of the stent may be more susceptible to neointimal hyperplasia. Regions of lower shear stress were recently shown to be associated with an enhanced rate of smooth muscle cell (SMC) migration after vascular injury (27). Nonuniform WSS also influenced cell density distributions, alignment, and migration direction in this model (28). In view of these previous findings, the present results indicate that vascular damage produced by stent expansion or use of a stent with wider struts may predispose this vascular segment to the development of neointimal hyperplasia by adversely affecting distributions of WSS. The present findings confirm and extend previous results examining neointimal hyperplasia in rabbit iliac arteries (39), indicating that reducing the number of stent struts may favorably improve WSS distributions.

Minimal differences in the vessel area exposed to spatial WSSG of $>20 \mathrm{dyn} / \mathrm{cm}^{3}$ within the stent were observed in the present investigation. However, the values of WSSG observed along the luminal surface immediately adjacent to stent struts were greater than those observed in normal vascular anatomic and flow conditions (22). Elevated spatial WSSG have been associated with cellular proliferation (46), and values of WSSG within simulated stents may exceed the threshold required to trigger molecular events associated with neointimal hyperplasia. Each simulation demonstrated that elevated WSSG were greatest at the stent inlet and outlet. WSSG gradients imparted on the stent itself were ignored in the present investigation, but Fig. 4 clearly demonstrates how regions adjacent to stent struts are subjected to elevated WSSG and theoretically susceptible to neointimal growth. Simulation of a stented vessel with cell growth adhering to the stent struts results in theoretical values of WSSG in excess of $300 \mathrm{dyn} / \mathrm{cm}^{3}$, as depicted in Fig. 5. Although some of these WSSG may be attributed to numerical artifacts generated by the flow solver, this additional simulation suggests that chronic cell proliferation may worsen WSSG around stent struts. Whether such a phenomenon contributes to further exacerbation of temporal fluid dynamics in vivo remains to be determined.

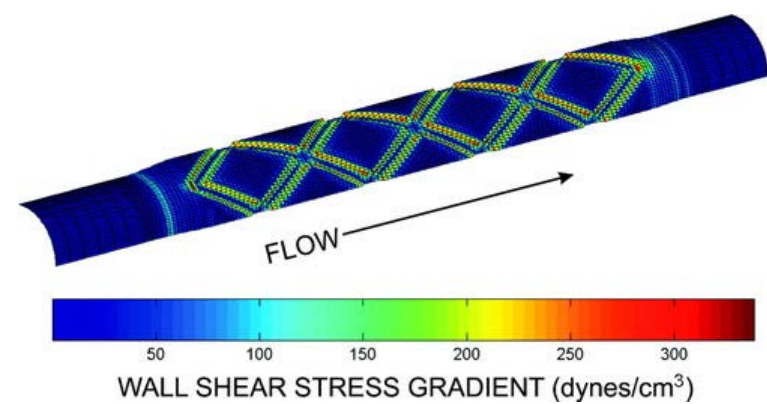

Fig. 5. Theoretical spatial WSSG imparted on the surface of a computational vessel after circulating cells have accumulated and covered the surface of the stent.

The computational stents generated here most closely resemble the Palmaz-Schatz slotted-tube design. Thus the present results may be clinically relevant because the Palmaz-Schatz stent is the most popular choice for congenital heart disease interventions that require stenting (19). Geometric differences between other commercially available stents and those modeled in the present investigation involve differences in the radial and axial stent properties that may substantially influence distributions of WSS. Stent design has become extremely elaborate, and results from the present simulation with a basic geometry may be applied to more intricate designs to gain insight about which geometric properties are most important in influencing flow dynamics. 
A previous study demonstrated that stent-to-artery deployment ratios equivalent to those studied in the present investigation may cause endothelial denudation in rabbit iliac arteries. Endothelial cells were absent from the vessel wall as a result of balloon injury during deployment in this previous study when the intra-strut spacing was approximately equal to that of the four-strut simulations presented in the present investigation. Conversely, a reduction in strut spacing (as modeled by the 8-strut simulation in our study) significantly limited the number of denuded endothelial cells in vivo (40). Removal of the endothelial layer allows direct transmission of WSS to SMCs. It is not presently known whether spatial WSSG influences SMC gene expression or proliferation in intact actual vessels. Some investigators have used spatial WSSG to quantify flow imparted on SMC distal to the internal elastic lamina (45) and platelet deposition in an abdominal aortic aneurysm (7) using CFD models. Nevertheless, the ability of SMC to act in a spatially coordinated fashion and differentially alter their mitotic expression in response to nonuniform distributions of WSS suggests that this assumption may be valid $(2,28,29,38)$.

The results should be interpreted within the constraints of several potential limitations. Each simulation was obtained with a stationary velocity boundary condition input into a rigid vessel. Thus our results may differ substantially from those obtained transiently or at the stent inlet and outlet in vivo because the blood vessel is distensible in these regions and a compliance-matching stent has been shown to limit flow disturbances distal to the stent outlet (3). Nevertheless, advanced atherogenesis and implantation of a slotted-tube stent both cause vascular rigidity (i.e., decreased compliance) $(24,49)$. A minimum of 68 time points would have been necessary to reconstruct the pulsatile waveform from which the velocity value in the present investigation was obtained. Each steady-state simulation was performed on a Silicon Graphics 02 5k Unix workstation with a MIPS R500 processor and $1 \mathrm{Gig}$ of RAM that allowed for simulation convergence after $72 \mathrm{~h}$. Fifteen simulations were necessary to investigate spatial mesh dependence. The results were considered spatially independent of the computational mesh when converging simulations with successively finer computational meshes varied by $<6 \%$ (35). Transient simulations would have required additional validation of temporal simulation results once the spatial mesh was determined. Hence, pulsatile simulations were beyond the computational resources available for the present investigation. The present simulation results were obtained assuming normal vascular anatomy with circular cross-sectional diameter, but the geometry of atherosclerotic lesions after stent implantation may or may not be circular depending on lesion composition $(34,41)$. Temporal endothelialization of the stented segment may eventually alter the local vascular geometry and distributions of WSS within the stented portion of the vessel but was not considered in the present investigation because previous in vitro and in vivo studies have shown that altered gene expression can occur within 1 day of shear-stress alterations and cellular damage $(16,27)$. These previous observations suggest that acute alterations in WSS after stent implantation may be of critical importance in determining the initiation of molecular mediators of neointimal hyperplasia.

In summary, the results obtained with 3D CFD modeling predict that varying the geometric properties and deployment ratio of a simulated stent alters the vascular distributions of WSS. These theoretical results suggest that stent geometries that minimize the number of stent intersections and reduce strut number and thickness are less likely to subject the vessel to distributions of WSS that have been implicated in the subsequent development of neointimal hyperplasia and restenosis.

\section{GRANTS}

This work was supported in part by National Institutes of Health Grants HL-03690 (to J. R. Kersten), HL-63705 (to J. R. Kersten), HL-54820 (to D. C. Warltier), and GM-08377 (to D. C. Warltier). 


\section{FOOTNOTES}

- The costs of publication of this article were defrayed in part by the payment of page charges. The article must therefore be hereby marked "advertisement" in accordance with 18 U.S.C. Section 1734 solely to indicate this fact.

The authors thank David A. Schwabe and John P. Tessmer for experimental support, Mary Lorence-Hanke for assistance in the preparation of this manuscript (Department of Anesthesiology, Medical College of Wisconsin), and Kristina Ropella and David Powers for technical support (Department of Biomedical Engineering and Olin Engineering Center, Marquette University, respectively).

\section{AUTHOR NOTES}

- Address for reprint requests and other correspondence: P. S. Pagel, Medical College of Wisconsin, MEBM4280, 8701 Watertown Plank Rd., Milwaukee, WI 53226 (E-mail: pspagel@mcw.edu).

\section{REFERENCES}

1 Benard N, Coisne D, Donal E, and Perrault R. Experimental study of laminar blood flow through an artery treated by a stent implantation: characterisation of intra-stent wall shear stress. J Biomech 36: 991998, 2003.

2 Berk BC. Vascular smooth muscle growth: autocrine growth mechanisms. Physiol Rev 81: 999-1030, 2001.

3 Berry JL, Manoach E, Mekkaoui C, Rolland PH, Moore JE Jr, and Rachev A. Hemodynamics and wall mechanics of a compliance matching stent: in vitro and in vivo analysis. J Vasc Interv Radiol 13: 97-105, 2002.

4 Berry JL, Santamarina A, Moore JE, Roychowdhury S, and Routh WD. Experimental and computational flow evaluation of coronary stents. Ann Biomed Eng 28: 386-398, 2000.

5 DePaola N, Gimbrone MA Jr, Davies PF, and Dewey CF. Vascular endothelium responds to fluid shear stress gradients. Arterioscler Thromb 12: 1254-1257, 1992.

6 Farb A, Sangiorgi G, Carter AJ, Walley VM, Edwards WD, Schwartz RS, and Virmani R. Pathology of acute and chronic coronary stenting in humans. Circulation 99: 44-52, 1999.

7 Finol EA and Amon CH. Blood flow in abdominal aortic aneurysms: pulsatile flow hemodynamics. $J$ Biomech Eng 123: 474-484, 2001.

8 Fischman DL, Leon MB, Baim DS, Schatz RA, Savage MP, Penn I, Detre K, Veltri L, Ricci D, and Nobuyoshi M. A randomized comparison of coronary-stent placement and balloon angioplasty in the treatment of coronary artery disease. Stent Restenosis Study Investigators. N Engl J Med 331: 496-501, 1994.

9 Fox RW and McDonald AT. Introduction to Fluid Mechanics. New York: Wiley, 1992.

10 Frank AO, Walsh PW, and Moore JE Jr. Computational fluid dynamics and stent design. Artif Organs 26: 614621, 2002.

11 Garasic JM, Edelman ER, Squire JC, Seifert P, Williams MS, and Rogers C. Stent and artery geometry determine intimal thickening independent of arterial injury. Circulation 101: 812-818, 2000.

12 Gunn J, Arnold N, Chan KH, Shepherd L, Cumberland DC, and Crossman DC. Coronary artery stretch versus deep injury in the development of in-stent neointima. Heart 88: 401-405, 2002.

13 Hoffmann R, Mintz GS, Dussaillant GR, Popma JJ, Pichard AD, Satler LF, Kent KM, Griffin J, and Leon MB. Patterns and mechanisms of in-stent restenosis. A serial intravascular ultrasound study. Circulation 94: 1247-1254, 1996.

14 Hoffman R, Mintz GS, Mehran R, Kent KM, Pichard AD, Satler LF, and Leon MB. Tissue proliferation within and surrounding palmaz-schatz stents is dependent on the aggressiveness of stent implantation technique. Am J Cardiol 83: 1170-1174, 1999. 
15 Holmes DR Jr, Hirshfeld J Jr, Faxon D, VlietstraR, Jacobs A, and King SB III. ACC expert consensus document on coronary artery stents. Document of the American College of Cardiology. J Am Coll Cardiol 32: 14711482, 1998.

16 Jones SM and Kazlauskas A. Connecting signaling and cell cycle progression in growth factor-stimulated cells. Oncogene 19: 5558-5567, 2000.

17 Kastrati A, Mehilli J, Dirschinger J, Pache J, Ulm K, Schuhlen H, Seyfarth M, Schmitt C, Blasini R, Neumann FJ, and Schomig A. Restenosis after coronary placement of various stent types. Am J Cardiol 87: 3439, 2001.

18 Kleinstreuer C, Hyun S, Buchanan JR Jr, Longest PW, Archie JP Jr, and Truskey GA. Hemodynamic parameters and early intimal thickening in branching blood vessels. Crit Rev Biomed Eng 29: 1-64, 2001.

19 Kreutzer J and Rome JJ. Open-cell design stents in congenital heart disease: a comparison of IntraStent vs. Palmaz stents. Catheter Cardiovasc Interv 56: 400-409, 2002.

$20 \mathrm{Ku}$ DN. Blood flow in arteries. Ann Rev Fluid Mech 29: 399-434, 1997.

$21 \mathrm{Ku}$ DN, Giddens DP, Zarins CK, and Glagov S. Pulsatile flow and atherosclerosis in the human carotid bifurcation. Positive correlation between plaque location and low oscillating shear stress. Arteriosclerosis 5: 293-302, 1985.

22 Kute SM and Vorp DA. The effect of proximal artery flow on the hemodynamics at the distal anastomosis of a vascular bypass graft: computational study. J Biomech Eng 123: 277-283, 2001.

23 LaDisa JF Jr, Guler I, Olson LE, Hettrick DA, Kersten JR, Warltier DC, and Pagel PS. Three-dimensional computational fluid dynamics modeling of alterations in coronary artery wall shear stress produced by stent implantation. Ann Biomed Eng 31: 972-980, 2003.

24 LaDisa JF Jr, Hettrick DA, Olson LE, Guler I, Gross ER, Kress TT, Kersten JR, Warltier DC, and Pagel PS. Coronary stent implantation alters coronary artery hemodynamics and wall shear stress during maximal vasodilation. J Appl Physiol 93: 1939-1946, 2002.

25 Lei M, Kleinstreuer C, and Archie JP Jr. Geometric design improvements for femoral graft-artery junctions mitigating restenosis. J Biomech 29: 1605-1614, 1996.

26 Lei M, Kleinstreuer C, and Truskey GA. A focal stress gradient-dependent mass transfer mechanism for atherogenesis in branching arteries. Med Eng Phys 18: 326-332, 1996.

27 Liu SQ and Goldman J. Role of blood shear stress in the regulation of vascular smooth muscle cell migration. IEEE Trans Biomed Eng 48: 474-483, 2001.

28 Liu SQ, Tang D, Tieche C, and Alkema PK. Pattern formation of vascular smooth muscle cells subjected to nonuniform fluid shear stress: mediation by the gradient of cell density. Am J Physiol Heart Circ Physiol 285: H1072-H1080, 2003.

29 Liu SQ, Tieche C, Dalin T, and Alkema P. Pattern formation of vascular smooth muscle cells subject to nonuniform fluid shear stress: role of platelet-derived growth factor $\beta$-receptor and Src. Am J Physiol Heart Circ Physiol 285: H1081-H1090, 2003.

30 Liu SQ, Zhong L, and Goldman J. Control of the shape of a thrombus-neointima-like structure by blood shear stress. J Biomech Eng 124: 30-36, 2002.

31 Malek AM, Alper SL, and Izumo S. Hemodynamic shear stress and its role in atherosclerosis. JAMA 282: 2035-2042, 1999.

32 McLean DR and Eigler NL. Stent design: implications for restenosis. Rev Cardiovasc Med 3, Supp/ 5: S16S22, 2002.

33 Moore JE Jr, Xu C, Glagov S, Zarins CK, and Ku DN. Fluid wall shear stress measurements in a model of the human abdominal aorta: oscillatory behavior and relationship to atherosclerosis. Atherosclerosis 110: 225-240, 1994. 
34 Murata T, Hiro T, Fujii T, Yasumoto K, Murashige A, Kohno M, Yamada J, Miura T, and Matsuzaki M. Impact of the cross-sectional geometry of the post-deployment coronary stent on in-stent neointimal hyperplasia: an intravascular ultrasound study. Circ J 66: 489-493, 2002.

35 Myers JG, Moore JA, Ojha M, Johnston KW, and Ethier CR. Factors influencing blood flow patterns in the human right coronary artery. Ann Biomed Eng 29: 109-120, 2001.

36 Newman VS, Berry JL, Routh WD, Ferrario CM, and Dean RH. Effects of vascular stent surface area and hemodynamics on intimal thickening. J Vasc Interv Radiol 7: 387-393, 1996.

37 Ojha M. Spatial and temporal variations of wall shear stress within an end-to-side arterial anastomosis model. J Biomech 26: 1377-1388, 1993.

38 Palumbo R, Gaetano C, Melillo G, Toschi E, Remuzzi A, and Capogrossi MC. Shear stress downregulation of platelet-derived growth factor receptor- $\beta$ and matrix metalloprotease- 2 is associated with inhibition of smooth muscle cell invasion and migration. Circulation 102: 225-230, 2000.

39 Rogers $C$ and Edelman ER. Endovascular stent design dictates experimental restenosis and thrombosis. Circulation 91: 2995-3001, 1995.

40 Rogers C, Tseng DY, Squire JC, and Edelman ER. Balloon-artery interactions during stent placement: a finite element analysis approach to pressure, compliance, and stent design as contributors to vascular injury. Circ Res 84: 378-383, 1999.

41 Schulz C, Herrmann RA, Beilharz C, Pasquantonio J, and Alt E. Coronary stent symmetry and vascular injury determine experimental restenosis. Heart 83: 462-467, 2000.

42 Serruys P, De Jaegere P, Kiemeneij F, Macaya C, Rutch W, Heyndrickx G, Emanuelsson H, Marco J, Legrand V, Materne P, Belardi J, Sigwart U, Colombo A, Goy JJ, van den Havval P, Delcan J, and Morel MA. A comparison of balloon-expandible-stent implantation with balloon angioplasty in patients with coronary heart disease. Benestent Study Group. N Engl J Med 331: 489-495, 1994.

43 Simon C, Palmaz JC, and Sprague EA. Influence of topography on endothelialization of stents: clues for new designs. J Long Term Eff Med Implants 10: 143-151, 2000.

44 Stone PH, Coskun AU, Kinlay S, Clark ME, Sonka M, Wahle A, llegbusi OJ, Yeghiazarians Y, Popma JJ, Orav J, Kuntz RE, and Feldman CL. Effect of endothelial shear stress on the progression of coronary artery disease, vascular remodeling, and in-stent restenosis in humans: in vivo 6-month follow-up study. Circulation 108: 438-444, 2003.

45 Tada $\mathrm{S}$ and Tarbell JM. Flow through internal elastic lamina affects shear stress on smooth muscle cells (3D simulations). Am J Physiol Heart Circ Physiol 282: H576-H584, 2002.

46 Tardy Y, Resnick N, Nagel T, Gimbrone MA, and Dewey CF. Shear stress gradients remodel endothelial monolayers in vitro via a cell proliferation-migration-loss cycle. Arterioscler Thromb Vasc Biol 17: 31023106, 1997.

47 Van Belle E, Tio FO, Couffinhal T, Maillard L, Pesseri J, and Isner JM. Stent endothelialization: time course, impact of local catheter delivery, feasibility of recombinant protein administration, and response to cytokine expedition. Circulation 95: 438-448, 1997.

48 Van Beusekom HM, Whelan DM, Hofma SH, Krabbendam SC, van Hinsbergh VW, Verdouw PD, and van der Giessen WJ. Long-term endothelial dysfunction is more pronounced after stenting than after balloon angioplasty in porcine coronary arteries. J Am Coll Cardiol 32: 1109-1117, 1998.

49 Vernhet $\mathrm{H}$, Juan JM, Demaria R, Olivia-Lauraire $\mathbf{M}$, Senac J, and Dauzat $\mathbf{M}$. Acute changes in aortic wall mechanical properties after stent placement in rabbits. J Vasc Interv Radiol 11: 634-638, 2000.

50 Yoshitomi Y, Kojima S, Yano M, Sugi T, Matsumoto Y, Saotome M, Tanaka K, Endo M, and Kuramochi M. Does stent design affect probability of restenosis? A randomized trial comparing Multilink stents with GFX stents. Am Heart J 142: 445-451, 2001. 